This item was submitted to Loughborough's Research Repository by the author.

Items in Figshare are protected by copyright, with all rights reserved, unless otherwise indicated.

\title{
Analysis of rapid manufacturing —using layer manufacturing processes for production
}

PLEASE CITE THE PUBLISHED VERSION

PUBLISHER

(C) Professional Engineering Publishing

LICENCE

CC BY-NC-ND 4.0

REPOSITORY RECORD

Hopkinson, Neil, and Phill M. Dickens. 2019. "Analysis of Rapid Manufacturing—using Layer Manufacturing Processes for Production”. figshare. https://hdl.handle.net/2134/3561. 
This item was submitted to Loughborough's Institutional Repository by the author and is made available under the following Creative Commons Licence conditions.

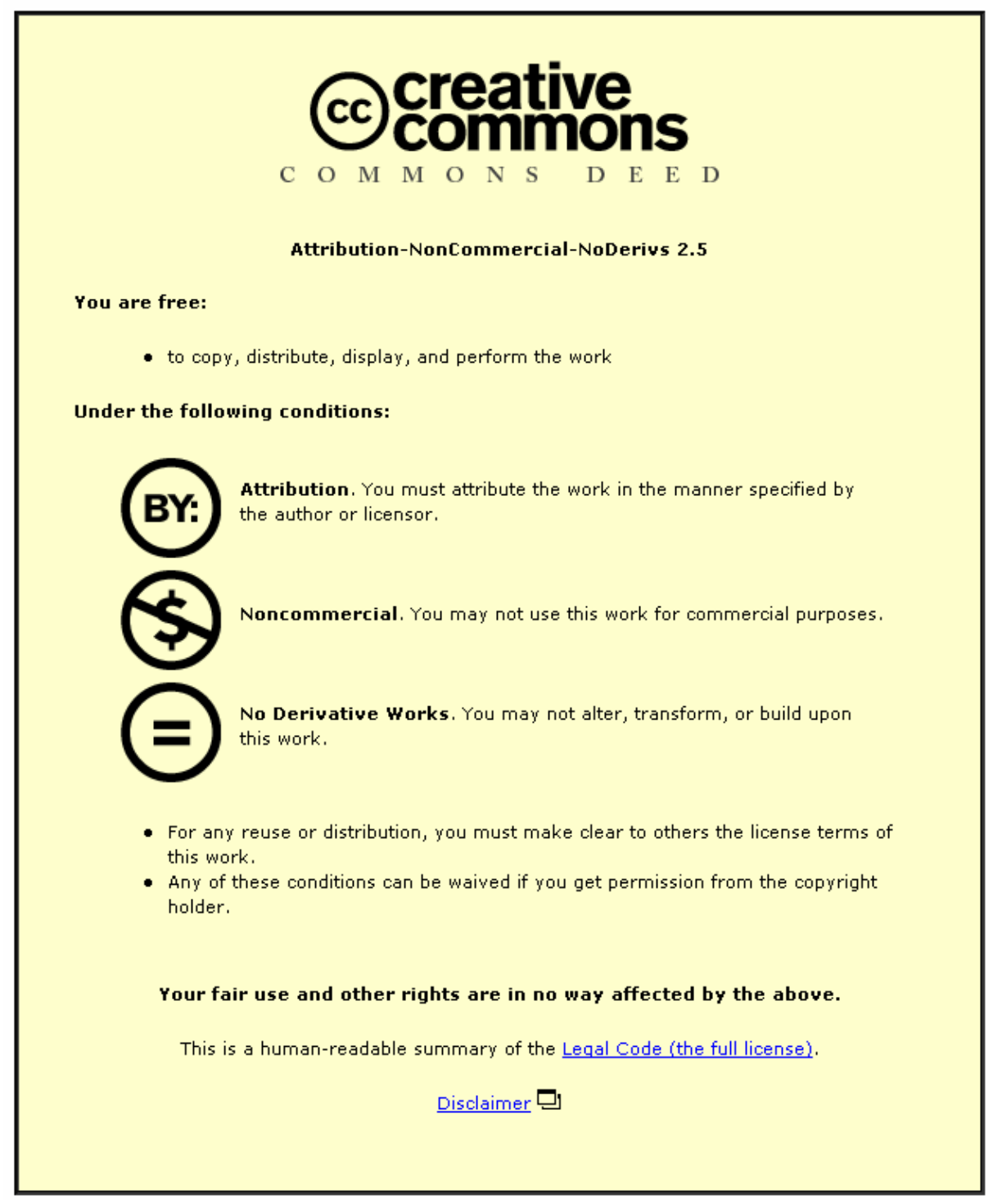

For the full text of this licence, please go to: http://creativecommons.org/licenses/by-nc-nd/2.5/ 


\title{
Analysis of rapid manufacturing-using layer manufacturing processes for production
}

N Hopkinson* and P Dickens

Wolfson School of Mechanical and Manufacturing Engineering, Loughborough University, Loughborough, UK

\begin{abstract}
Rapid prototyping (RP) technologies that have emerged over the last 15 years are all based on the principle of creating three-dimensional geometries directly from computer aided design (CAD) by stacking two-dimensional profiles on top of each other. To date most R P parts are used for prototyping or tooling purposes; however, in future the majority may be produced as end-use products. The term 'rapid manufacturing' in this context uses RP technologies as processes for the production of end-use products.

This paper reports findings from a cost analysis that was performed to compare a traditional manufacturing route (injection moulding) with layer manufacturing processes (stereolithography, fused deposition modelling and laser sintering) in terms of the unit cost for parts made in various quantities. The results show that, for some geometries, it is more economical to use layer manufacturing methods than it is to use traditional approaches for production in the thousands.
\end{abstract}

Keywords: rapid prototyping, rapid manufacturing, injection moulding, medium volume manufacture

\section{NOTATION}

$D$

E

FDMPC

FDMPM

FDMSC

FDMSM

HY

$L$

LCP

LSC

LSM

LSMC

LSMCP

LSMS

LSMU

$M$ machine depreciation per year (euros)

machine purchase cost (euros) model material cost for FDM (euros/kg) mass of model material per part for FDM $(\mathrm{kg})$ support material cost for FDM (euros $/ \mathrm{kg}$ ) mass of support material per part for FDM $(\mathrm{kg})$

hours per year in operation (h)

labour cost per build (euros)

labour cost per part (euros)

material cost for LS (euros $/ \mathrm{kg}$ )

mass per part for LS $(\mathrm{kg})$

cost of material used in one build for LS

(euros)

material cost per part for LS (euros)

mass of sintered material per build for LS

$(\mathrm{kg})$

mass of unsintered material per build for

LS (kg)

maintenance cost per year (euros)
The MS was received on 18 February 2002 and was accepted after revision for publication on 26 A pril 2002.

* Corresponding author: Wolfson School of Mechanical and Manufacturing Engineering, Loughborough University, Loughborough, Leicestershire LE11 $3 T U, U K$.

MC
MCP
$N$
Op
Post
$R$
Set
SLcost
SLMass
SLMCP

$T$
TBV
$V$
VP

total machine cost per year (euros)

machine cost per part (euros)

number of parts in a build

machine operator cost per hour (euros)

post-processing time for a build (h)

production rate $\left(\mathrm{h}^{-1}\right)$

set-up time for a build (h)

cost of SL material (euros/kg)

mass of material used per part for SL $(\mathrm{kg})$

cost of material used per part for SL

(euros)

time to complete one build (h)

total build volume for $\mathrm{LS}\left(\mathrm{cm}^{3}\right)$

production volume per year

part volume $\left(\mathrm{cm}^{3}\right)$

\section{INTRODUCTION}

Production volumes and product life cycles have both fallen in recent years. For example, the average life cycle for electronic products fell from 9 years to 4 years between 1965 and 1990 [1]; between 1981 and 1991 the product life cycle for car components fell by 27.6 per cent [2]. At the same time, increases in product diversity and satisfaction of market niches have grown.

Proc. Instn Mech. Engrs Vol. 217 Part C: J. Mechanical Engineering Science 
These trends have occurred over a period of 20-30 years, the latter half of this period having seen the development of rapid prototyping (RP) technologies. $\mathrm{RP}$ technologies are used to produce parts for various reasons, including functional models, fit/assembly and patterns for prototype tooling [3]. Although no clear idea of actual numbers is available, RP technologies are already being used for some small-volume manufacture [4]. As production volumes decrease, the application of $\mathrm{RP}$ technologies for production rapid manufacturing (RM) may grow significantly.

Before considering the application of $\mathrm{RM}$ as a suitable tool for manufacturing, any organization should be aware of the potential advantages and current limitations that exist. The advantages to be gained by adopting RP methods for manufacture may be broadly split into two categories, namely:

(a) advantages that are available today and

(b) advantages that may be expected in the future.

The focus of this paper is to highlight the capabilities of processes that exist today. However, future potential is of significant interest.

\subsection{Potential advantages to be gained from RM using current RP technology}

Today's RP processes offer clear advantages over current alternatives for production, such as injection moulding and machining, in a number of ways. RM allows geometric freedoms such as variable wall thickness and zero draft which injection moulding will not tolerate. Further geometric freedom is afforded to RM by the fact that no tooling is required that 'freezes' a design. Consequently, changes to part geometry, be they subtle or substantial, may be applied without the need to incur the times and costs of producing new tooling. The absence of tooling also takes away a significant cost in the product development process at an early stage. This should ease problems of cash flow-it should be noted that most companies that become bankrupt do so as a result of cash flow problems. Additionally, the lead times imposed by tooling may be removed by using RM. Manufacturing without tooling also allows distributed manufacture so that parts may be made in or near the location where they are required, rather than being moulded at one production facility and shipped to the required destination. This simplified distribution may be particularly useful for the provision of replacement parts etc. as it will also obviate the need to store spares. An example of this may be seen by NASA's adoption of fused deposition modelling (FDM) to make spare parts on the international space station [5].

Unlike other manufacturing processes such as machining, a complex product costs the same and takes no longer to produce than a simple one of similar size when it is produced by $\mathrm{RM}$. RM processes minimize waste, which reduces the mass of material that needs to be purchased and the costs of disposal.

\subsection{Potential advantages to be gained from RM using future RP technology}

Future RP processes will offer advantages over alternative processes in their ability to produce geometries and structures that simply are not possible by other routes. It could be argued that the geometry freedoms described above are an early example of this. The additive processes used by RM will allow production of parts with functionally graded composition [6] and also with embedded electronics for monitoring or actuation purposes [7]. The scope for use of such parts is hard to imagine at this time, simply because the possibility for producing products in these ways has simply not been available in the past.

\subsection{Current limitations for RM}

The materials and properties of RP parts often fail to match their moulded or machined counterparts. However, it should be noted that using finite element analysis (FEA) techniques such parts are designed to be functional when made from moulded or machined stock material. If the material properties for R P parts were known in detail, e.g. across wide temperature ranges, then functional parts could be designed to be manufactured by RP processes. It is probably fair to say that the current limitation in material properties lies in the fact that they are not known sufficiently rather than they are simply not good enough.

Accuracy, detail and surface finish are all aspects of $\mathrm{RP}$ that have been a disadvantage when compared with other manufacturing processes. Consequently, these issues have received a great amount of research and seen significant improvements. However, in many aesthetic applications, post processing, which could offset any benefits of RM, may be required, leading to the use of alternative traditional approaches. For many non-visible parts, such as under-the-bonnet applications, surface finish is less of an issue and RM may be more suitable.

The high costs associated with machines, maintenance and materials for RP processes probably constitute the biggest barrier to RM at present. Economies of scale coupled with high $R \& D$ costs have rendered the RP industry as a high-cost area since its inception. However, increases in the adoption of the technology has resulted in some reduction of costs, with new machines entering the market at lower prices. Until RP technologies become more standard, maintenance costs are likely to remain relatively high. However, they should reduce 
with time and increased competition between suppliers. Similarly, material costs should reduce with increased use and competition for suppliers.

\subsection{Current examples of rapid manufacturing}

Boeing's Rocketdyne propulsion and power section has used laser sintering (LS) to manufacture low volumes of parts, such as those for the space lab and space shuttles [4]. NASA's Jet Propulsion Lab has also used LS to make parts launched into the upper atmosphere [8].

Align Technologies use stereolithography (SL) to produce one-off moulds for orthodontic aligners in the thousands [9]. Although the manufacture of moulds does not fit in with the definition of rapid manufacturing, the ability to increase SL throughput threefold by tuning the hardware and software to produce a standard type of geometry (a sort of cell manufacturing approach) is of particular interest. So successful has been the application of SL for this application that Align Technologies have purchased 50 machines for manufacturing.

The FBI have used SL to produce parts for surveillance operations, with over 4000 parts produced since 1994, the majority of which have been final products [10]. In one example, an a.c./d.c. converter in the form of a battery housing was produced in a quantity of 200 at a cost of US\$29 per converter compared to a quote of US\$1000 per converter from a non-RP supplier.

\section{COST ANALYSIS}

The purpose of this research is to provide a direct comparison between RM approaches with injection moulding for the manufacture of selected geometries in various quantities. The cost analysis was performed in a manner that assumed that production criteria may be applied to RP machines; e.g. machine depreciation was set as 8 years, straight line for RP machines, as this was used for injection moulding equipment. Also, using the RP machine for production means that the preprocessing time, such as part orientation and placement, is reduced as standard builds would be used. It was assumed that an RP machine would achieve 90 per cent uptime (as would an injection moulding machine) if used for production. This is a fair assumption given that organizations that currently use RP machines for highvolume manufacture achieve such high levels of uptime. These assumptions, which have a significant bearing on part costs, allow for a fair comparison between injection moulding and the RP processes. The costs for injection moulding were obtained by quotes for tooling plus unit costs for each moulding produced.

\subsection{Assumptions}

During initial calculations for costs, factors such as machine power consumption and space rental had been considered. However, these contributed such a small total to the final costs (less than 1 per cent) that they have not been included. No inclusion of overhead costs, such as for part design and testing, etc., have been included as these were not included in the quotes for costs by injection moulding.

The costs for producing parts by R P processes were broken down into:

(a) machine costs,

(b) labour costs,

(c) material costs.

A significant assumption is that the material properties, surface finish and accuracy of parts produced by RP are not an issue. This is clearly very important although it should be borne in mind that the products were designed for manufacture by moulding-in order to be functional RM parts the design may need to be changed.

\subsection{Methodology}

Costs for producing parts by $\mathrm{RM}$ were calculated by assuming that a machine produces one part consistently for 1 year, although one of the benefits of $\mathrm{RM}$ is the ability to simultaneously produce numerous parts, say a complete assembly, on a single machine. In each case, the maximum number of parts that may be built by a machine in one build were manufactured and the costs generated by the following calculations.

\subsubsection{Calculating machine costs}

Table 1 shows the build parameters and machine costs that were considered. These were required to formulate the total machine cost per part produced by each of the $\mathrm{RP}$ processes. Costs for ancillary equipment vary according to location; e.g. air-conditioning systems depend on the climate in which the machine is located. Ancillary costs for RP machines play only a very small percentage of the total price for the machinery; for this reason, basic machine costs from manufacturers have been used. In each case, the highest rate of maintenance cost currently available from the equipment supplier was used.

\subsubsection{Calculating labour costs}

Table 2 shows the build parameters and labour costs that were required to formulate the labour costs per part for each RP process used. An hourly rate of 5.30 euros was used for injection moulding, remembering that for 
Table 1 Calculation of machine costs

\begin{tabular}{lll}
\hline & \multicolumn{2}{c}{ Source of cost } \\
\cline { 2 - 3 } & Variable & Obtained by \\
\hline Number per platform & $N$ & Maximum possible in one build \\
Platform build time & $T$ & Hours \\
Production rate per hour & $R$ & $N / T$ \\
Hours per year in operation & $\mathrm{HY}$ & $365 \times 24 \times 90 \%=7884$ \\
Production volume total per year & $V$ & $R \times 7884$ \\
& & \\
Machine costs & & \\
Machine and ancillary equipment & $E$ & Machine purchase cost \\
Equipment depreciation per year & $D$ & $E / 8$ \\
Machine maintenance per year & $M$ & Most comprehensive package \\
Total machine cost per year & MC & $D+M$ \\
Machine cost per part & MCP & MC/V \\
\hline
\end{tabular}

Table 2 Calculation of labour costs

\begin{tabular}{lll}
\hline & \multicolumn{2}{c}{ Source of cost } \\
\cline { 2 - 3 } & Variable & Obtained by \\
\hline Number per platform & $N$ & Maximum possible in one build \\
Platform build time & $T$ & Hours \\
Production rate per hour & $R$ & $N / T$ \\
Hours per year in operation & $\mathrm{HY}$ & $365 \times 24 \times 90 \%=7884$ \\
Production volume total per year & $V$ & $R \times \mathrm{HY}$ \\
& & \\
Labour costs & & \\
Machine operator cost per hour & Op & Minimum wage 5.30 euros \\
Set-up time to control machine & Set & Timed \\
Post-processing time per build & Post & Timed \\
Labour cost per build & $L$ & Op $\times($ Set + Post $)$ \\
Labour cost per part & LCP & $L / N$ \\
\hline
\end{tabular}

production purposes, highly skilled staff would not be needed.

\subsubsection{Calculating material costs}

The method for calculating material costs for each process is shown in Table 3. The different nature of the three RP processes employed necessitated the use of slightly different means for calculating material costs. For SL, it was sufficient to weigh completed parts with supports in order to calculate material costs; this assumes that no material is wasted by replacing vats, etc.

In the case of fused deposition modelling (FDM), it was sufficient to weigh parts and support separately and then to multiply these by the associated material costs to find the material cost. In this case, the weight of purged material that is used in the build process was not considered. A more complex system to calculate costs with LS was required. It was assumed that no material was to be recycled to ensure consistent part quality (although in practice material is recycled and some organizations practising $\mathrm{RM}$ could recycle material without compromising part functionality, depending on their product's function). The mass of material used was calculated in terms of sintered material (by weighing parts) and unsintered material (by calculating the volume of unused material and multiplying this by its unsintered density).

\subsection{Parts selected}

A number of RP processes are currently available commercially, each with its own strengths and weaknesses. As a general rule, RP techniques are suited to producing small parts with a lot of geometry and this immediately suggests the focus of RM for smallish products. In this work, one part was selected as it is small and has a complex geometry (see Fig. 1).

For comparison, the second part was of medium size and complex geometry (see Fig. 2). A hypothesis could be made that the smaller parts should be more suited to $\mathrm{RM}$ due to their size. 


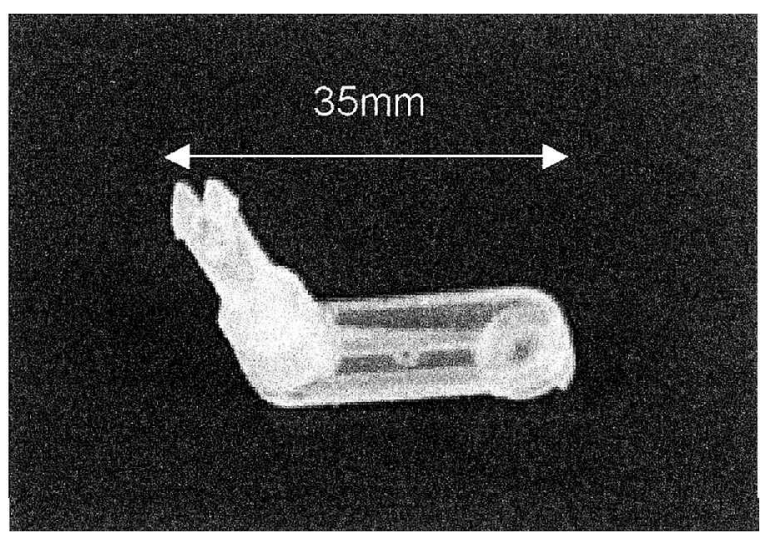

Fig. 1 Small lever part selected for cost analysis

\section{RESULTS}

\subsection{Injection moulding}

Costs for injection moulding were obtained by quote and are summarized in Table 4 . It can be seen that the cost of the tool far outweighs the unit cost for each additional part. Also, the tool for the cover is not significantly higher than that for the lever, despite it being much larger. The unit costs for each moulding are almost equal as the lever parts were moulded in polycarbonate, which is more expensive than polypropylene in which the cover parts were moulded.

\subsection{Stereolithography}

Table 5 shows the building parameters and cost associated with SL when building both parts in epoxy on an SLA7000 machine. A more detailed breakdown of the costs for SL can be seen in Table 6. The lever part costs around one-tenth of the cover and in both cases the majority of the cost ( $\sim 70$ per cent $)$ is attributed to machine costs. The material cost comprises around 30 per cent of the cost for each part and labour is negligible.

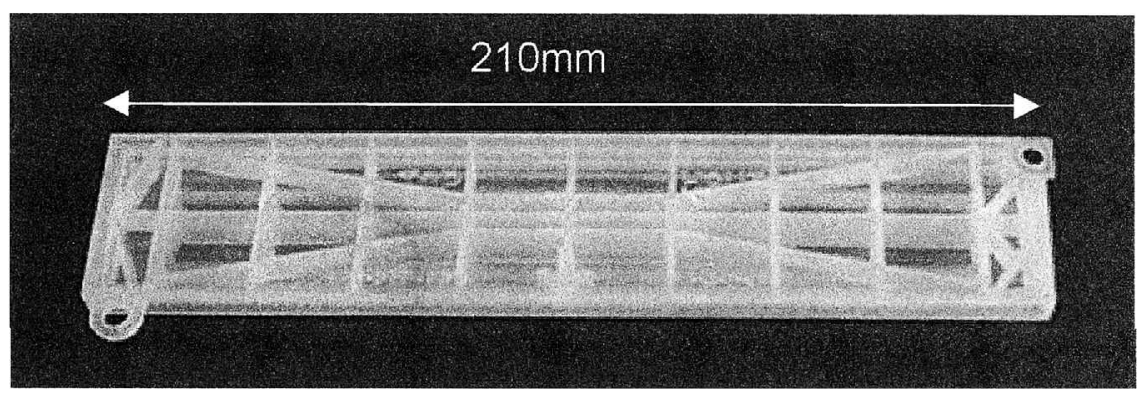

Fig. 2 Medium-sized cover part selected for cost analysis

Table 3 Calculation of material costs for each process

\begin{tabular}{|c|c|c|}
\hline & \multicolumn{2}{|r|}{ Source of cost } \\
\hline & Variable & Obtained by \\
\hline Number per platform & $N$ & Maximum possible in one build \\
\hline \multicolumn{3}{|l|}{ Material costs for $S L$} \\
\hline Material per part including support $(\mathrm{kg})$ & SLMass & Weighing finished parts \\
\hline Material cost per $\mathrm{kg}$ & SLcost & Quote $=275.20$ euros \\
\hline Material cost per SL part & SLMCP & SLMAss $\times$ SLcost \\
\hline \multicolumn{3}{|l|}{ Material costs for FDM } \\
\hline Material per part $(\mathrm{kg})$ & FDMPM & Weighing finished parts \\
\hline Support material per part (kg) & FDMSM & Weighing finished supports \\
\hline Build material cost per $\mathrm{kg}$ & FDMPC & Quote $=400.00$ euros \\
\hline Support material cost per $\mathrm{kg}$ & FDMSC & Quote $=216.00$ euros \\
\hline Material cost per FDM part & & $(\mathrm{FDMPM} \times \mathrm{FDMPC})+(\mathrm{FDMSM} \times \mathrm{FDMSC})$ \\
\hline \multicolumn{3}{|l|}{ Material costs for $L S$} \\
\hline Material cost per $\mathrm{kg}$ & LSC & Quote $=54.00$ euros \\
\hline Mass of each part & LSM & Weighing finished parts \\
\hline Volume of each part & VP & Found with Magics software \\
\hline Total build volume & TBV & $34 \times 34 \times 60 \mathrm{~cm}^{3}$ \\
\hline Mass of sintered material per build & LSMS & $N \times \mathrm{LSM}$ \\
\hline Mass of unsintered material per build & LSMU & $(\mathrm{TBV}-N \times \mathrm{VP}) \times 0.475^{*}$ \\
\hline Cost of material used in one build & LSMC & $(\mathrm{LSMU}+\mathrm{LSMS}) \times \mathrm{LSC}$ \\
\hline Material cost per LS part & LSMCP & $\mathrm{LSMC} / \mathrm{N}$ \\
\hline
\end{tabular}

* Published density of unsintered LS powder is $0.45-0.5 \mathrm{~g} / \mathrm{cm}^{3}[\mathbf{1 1}]$. 
Table 4 Costs for injection moulding

\begin{tabular}{lll}
\hline & \multicolumn{2}{c}{ Part name } \\
\cline { 2 - 3 } & Lever & \multicolumn{1}{c}{ Cover } \\
\hline Tool cost (euro) & 27360 & 32100 \\
Unit cost (euro) & 0.23 & 0.21 \\
\hline
\end{tabular}

Table 5 Costs for producing parts by stereolithography

\begin{tabular}{lll}
\hline & \multicolumn{2}{c}{ Part name } \\
\cline { 2 - 3 } & Lever & Cover \\
\hline Number per platform & 190 & 22 \\
Machine cost per part (euro) & 3.92 & 31.22 \\
Labour cost per part (euro) & 0.04 & 0.39 \\
Material cost per part (euro) & 1.29 & 15.16 \\
& & \\
Total cost per part (euro) & 5.25 & 46.78 \\
\hline
\end{tabular}

\subsection{Fused deposition modelling}

Table 7 shows the building parameters and cost associated with FDM when building both parts in ABS on an FDM 2000 machine; a more detailed breakdown of the costs for FDM can be seen in Table 8. The costs for FDM are slightly lower totals than those found with SL. As with SL, the lever part costs around

Table 6 Detailed cost breakdown for stereolithography

\begin{tabular}{lll}
\hline & \multicolumn{2}{c}{ Part name } \\
\cline { 2 - 3 } & Lever & Cover \\
\hline Number per platform & 190 & 22 \\
Platform build time (h) & 26.80 & 24.73 \\
Production rate per hour (h ${ }^{-1}$ ) & 7.09 & 0.89 \\
Hours per year in operation (h) & 7884 & 7884 \\
Production volume total per year & 55894 & 7014 \\
& & \\
Machine costs & & \\
Machine and ancillary equipment (euro) & 1040000 & 1040000 \\
Equipment depreciation cost per year (euro) & 130000 & 130000 \\
Machine maintenance cost per year (euro) & 89000 & 89000 \\
Total machine cost per year (euro) & 219000 & 219000 \\
Machine cost per part (euro) & 3.92 & 31.22 \\
& & \\
Labour costs & & \\
Machine operator cost per hour (euro) & 5.30 & 5.30 \\
Set-up time to control machine (min) & 33 & 30 \\
Post-processing time per build (min) & 49 & 68 \\
Labour cost per build (euro) & 7.24 & 8.65 \\
Labour cost per part (euro) & 0.04 & 0.39 \\
Material costs & & \\
Material per part including support (kg) & 0.0047 & 0.0551 \\
Material cost per kg (euro) & 275.20 & 275.20 \\
Material cost per part (euro) & 1.29 & 15.16 \\
& & \\
Total cost per part (euro) & 5.25 & 46.78 \\
\hline
\end{tabular}

Table 7 Costs for producing parts by fused deposition modelling

\begin{tabular}{lll}
\hline & \multicolumn{2}{c}{ Part name } \\
\cline { 2 - 3 } & Lever & Cover \\
\hline Number per platform & 75 & 4 \\
Machine cost per part (euro) & 2.64 & 23.12 \\
Labour cost per part (euro) & 0.08 & 0.33 \\
Material cost per part (euro) & 1.75 & 21.83 \\
Total cost per part (euro) & 4.47 & 45.28 \\
\hline
\end{tabular}

Table 8 Detailed cost breakdown for fused deposition modelling

\begin{tabular}{|c|c|c|}
\hline & \multicolumn{2}{|c|}{ Part name } \\
\hline & Lever & Cover \\
\hline Number per platform & 75 & 4 \\
\hline Platform build time (h) & 67.27 & 31.40 \\
\hline Production rate per hour $\left(\mathrm{h}^{-1}\right)$ & 1.11 & 0.13 \\
\hline Hours per year in operation (h) & 7884 & 7884 \\
\hline Production volume total per year & 8790 & 1004 \\
\hline \multicolumn{3}{|l|}{ Machine costs } \\
\hline Machine and ancillary equipment (euro) & 101280 & 101280 \\
\hline Equipment depreciation cost per year (euro) & 12660 & 12660 \\
\hline Machine maintenance cost per year (euro) & 10560 & 10560 \\
\hline Total machine cost per year (euro) & 23220 & 23220 \\
\hline Machine cost per part (euro) & 2.64 & 23.12 \\
\hline \multicolumn{3}{|l|}{ Labour costs } \\
\hline Machine operator cost per hour (euro) & 5.30 & 5.30 \\
\hline Set-up time to control machine (min) & 10 & 10 \\
\hline Post-processing time per build (min) & 60 & 5 \\
\hline Labour cost per build (euro) & 6.18 & 1.32 \\
\hline Labour cost per part (euro) & 0.08 & 0.33 \\
\hline \multicolumn{3}{|l|}{ Material costs } \\
\hline Material per part $(\mathrm{kg})$ & 0.0035 & 0.04 \\
\hline Support material per part $(\mathrm{kg})$ & 0.0016 & 0.027 \\
\hline Build material cost per kg (euro) & 400.00 & 400.00 \\
\hline Support material cost per kg (euro) & 216.00 & 216.00 \\
\hline Material cost per part (euro) & 1.75 & 21.83 \\
\hline Total cost per part (euro) & 4.47 & 45.28 \\
\hline
\end{tabular}

one-tenth of the cover and in both cases the majority of the cost $(\sim 50-60$ per cent $)$ is attributed to machine costs. As with SL, the labour cost is negligible; however, material costs are higher than those for SL.

An alternate option with FDM is to use the waterworks system with soluble supports. This increases the cost of the equipment and support material but obviates the need for manual finishing. A cost analysis was performed which showed that part costs were higher using the waterworks system than the one used in this research with expected costs of 4.80 and 48.75 euros for the lever and cover respectively. 
Table 9 Costs for producing parts by laser sintering

\begin{tabular}{lll}
\hline & \multicolumn{2}{c}{ Part name } \\
\cline { 2 - 3 } & Lever & Cover \\
\hline Number per platform & 1056 & - \\
Machine cost per part (euro) & 0.52 & - \\
Labour cost per part (euro) & 0.04 & - \\
Material cost per part (euro) & 1.63 & - \\
Total cost per part (euro) & 2.20 & - \\
\hline
\end{tabular}

\subsection{Laser sintering}

Table 9 shows the building parameters and cost associated with LS when building the lever part in nylon on an EOSP360 machine. A more detailed breakdown of the costs for LS can be seen in Table 10; the cover parts were not built by LS.

The costs for LS appear to be significantly cheaper than those for SL and FDM. In the case of LS, material provided the highest cost as it was assumed that none of the unsintered material could be recycled. Close inspection of Table 10 shows that sintered material only comprised one-tenth of the material used for the lever; with more efficient packing of parts, the cost should be able to be reduced significantly. The machine costs for

Table 10 Detailed cost breakdown for laser sintering

\begin{tabular}{lll}
\hline & \multicolumn{2}{c}{ Part name } \\
\cline { 2 - 3 } & Lever & Cover \\
\hline Number per platform & 1056 & - \\
Platform build time (h) & 59.78 & - \\
Production rate per hour (h ${ }^{-1}$ ) & 17.66 & - \\
Hours per year in operation (h) & 7884 & - \\
Production volume total per year & 139269 & - \\
Machine costs & & \\
Machine and ancillary equipment (euro) & 340000 & - \\
Equipment depreciation cost per year (euro) & 42500 & - \\
Machine maintenance cost per year (euro) & 30450 & - \\
Total machine cost per year (euro) & 72950 & - \\
Machine cost per part (euro) & 0.52 & - \\
Labour costs & & - \\
Machine operator cost per hour (euro) & 5.30 & - \\
Set-up time to control machine (min) & 120 & - \\
Post-processing time per build (min) & 360 & - \\
Labour cost per build (euro) & 42.37 & - \\
Labour cost per part (euro) & 0.04 & - \\
Material costs & & - \\
Material cost per kg (euro) & 5.3 & - \\
Mass of each part (kg) & 3.8016 & - \\
Volume of each part (cm ${ }^{3}$ ) & 1725.72 & - \\
Mass of sintered material per build (kg) & 1.63 & - \\
Cost of material used in one build (euro) & 2.20 & - \\
Material cost per part (euro) & & - \\
Total cost per part (euro) & & - \\
\hline & & - \\
\hline
\end{tabular}

C01702 (C) IMechE 2003
LS are lower than for the other processes, mainly because the machine is capable of building a higher number of parts by stacking vertically and because the build rate is higher.

\subsection{Comparisons for the lever}

Figure 3 shows a cost comparison for the lever according to production volume when produced by each method. As expected, injection moulding is the most expensive process for small volumes due to the cost of tooling. SL and FDM both appear to be more suitable methods of manufacture than injection moulding for volumes up to around 6000. LS, which incurs a unit cost of around half of that for SL and FDM, appears to be a more viable option than injection moulding for production volumes up to around 14000 . The reducing slope of the injection moulding cost line indicates that a cost reduction of 25 per cent for LS would suggest an economical production volume up to around 20000 parts. As mentioned above, more efficient packing of parts in the build volume may achieve this kind of reduction in cost.

\subsection{Comparisons for the cover}

Figure 4 shows a cost comparison for the cover according to the production volume when produced by each method (except for LS). As with the lever, injection moulding is the most expensive process for small volumes due to the cost of tooling. SL and FDM appear to be suitable processes for volumes up to around 700, after which injection moulding is more viable. This cutoff volume is around one-tenth of that for the lever. This confirms that RP processes used in this research are more suitable for the production of smaller parts.

\section{CONCLUSIONS}

The cost analysis has helped to identify where the major sources of cost for rapid manufacturing are to be found. Machine costs play a major part in the costs of production by rapid manufacturing for SL, FDM and LS. Clearly, if RM were to be more widely adopted then economies of scale should allow reduced machine costs and consequently lower production costs. The cost of ancillary equipment will vary according to location and affect the machine cost. It should be noted that the ancillary equipment required for FDM is significantly lower than that for both LS and SL.

Labour costs appeared to be minimal for each of the processes considered, with material costs having a significant input, especially for LS. As with machine 


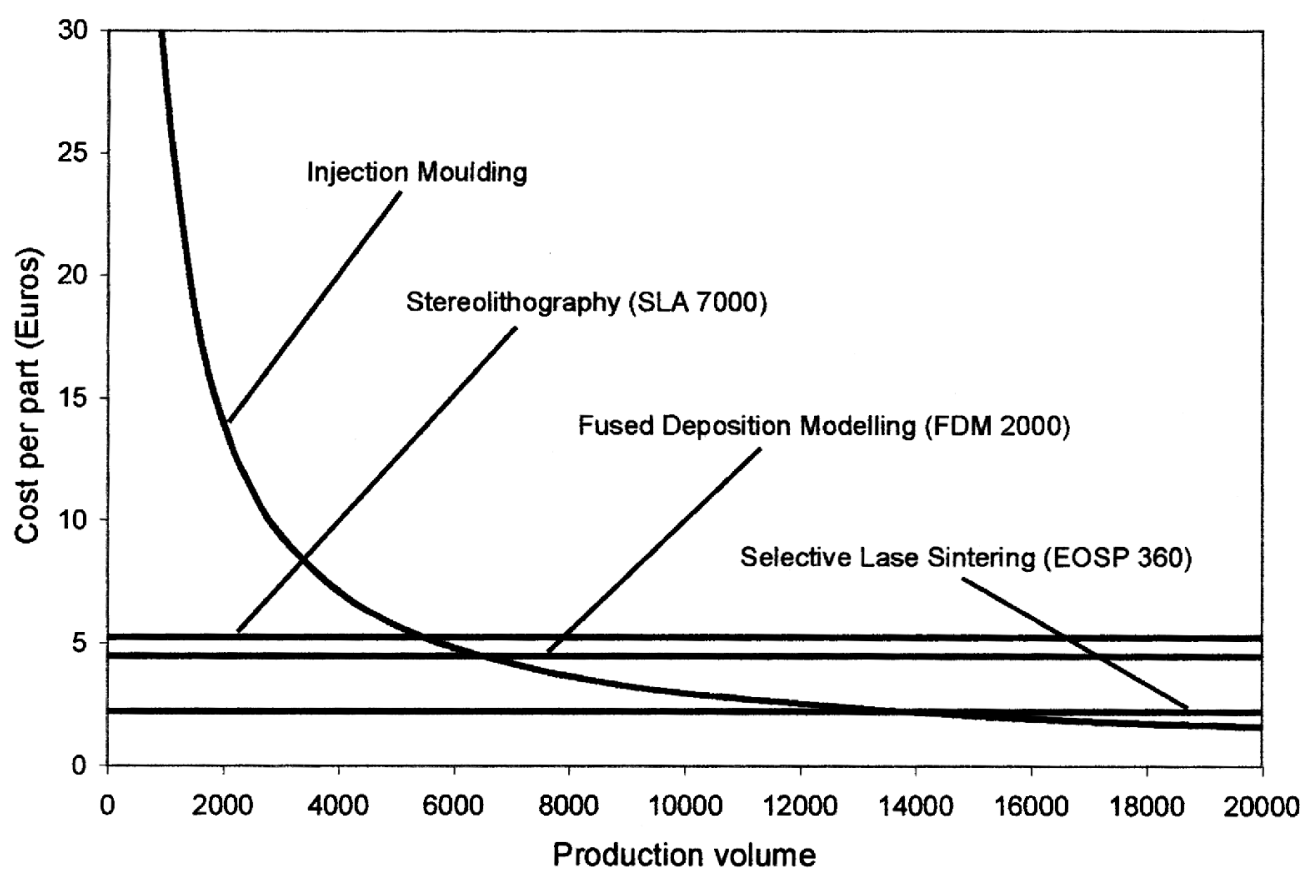

Fig. 3 Cost comparison for the lever by different processes

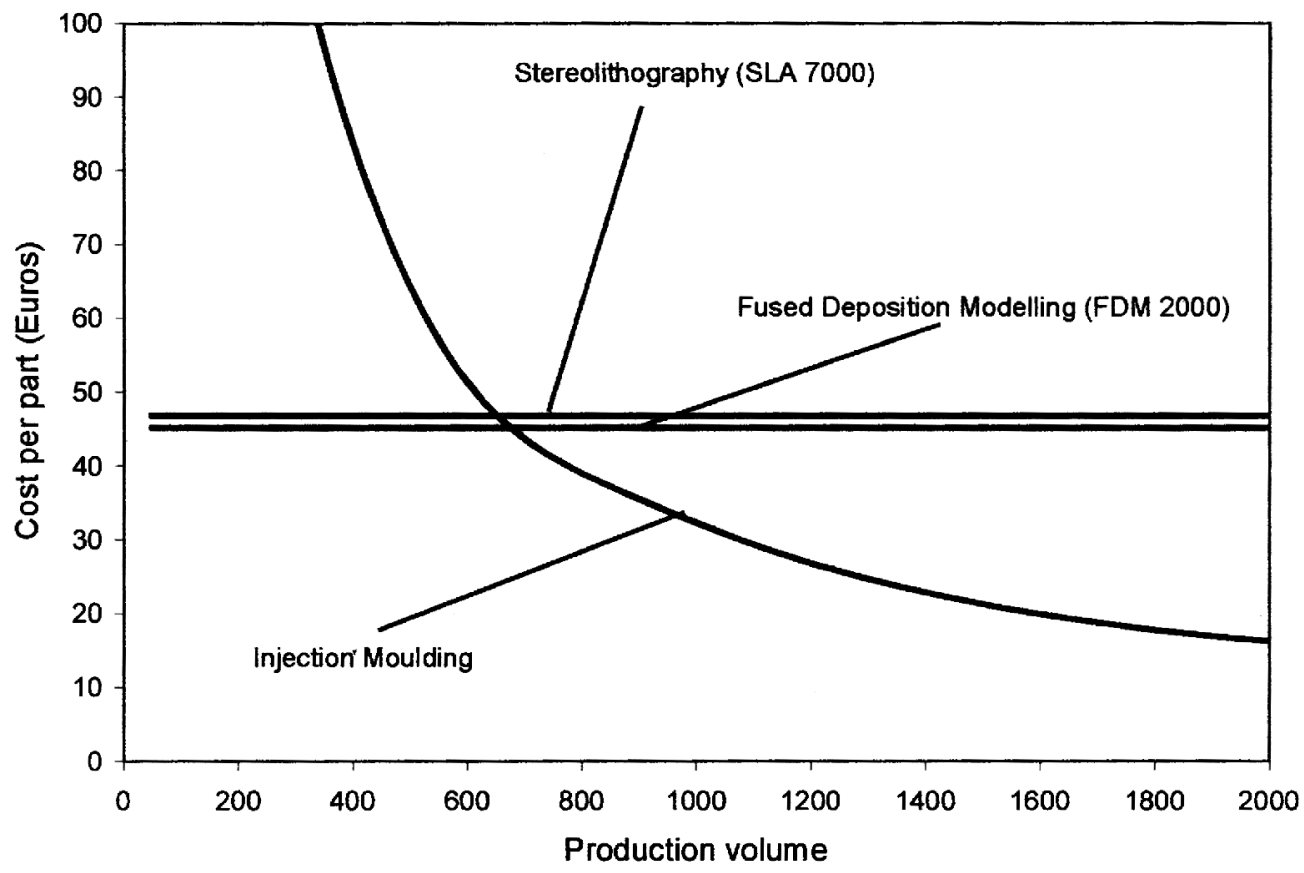

Fig. 4 Cost comparison for the cover by different processes

costs, more widespread adoption of RM would reduce material costs due to economies of scale. Refinement of machines and their software to assist RM, such as allowing more efficient packing of parts in the build volume, would also help to significantly reduce part costs and make RM a more viable production route.
Comparisons with injection moulding showed that RM may compete in cost terms with injection moulding for relatively high production volumes. In order for organizations to consider RM, issues such as material properties, fatigue resistance and surface finish will need to be fully understood and considered. 


\section{ACKNOWLEDGEMENTS}

The authors would like to thank the following individuals and organizations:

(a) Delphi Automotive Systems for supplying the parts and information for injection moulding,

(b) Volker Junior at EOS GmbH for making the LS parts,

(c) 3D Systems, Vantico and Stratasys for supporting the Rapid Manufacturing Consortium whose machines were used to build the SL and FDM parts.

\section{REFERENCES}

1 Ettlie, J. and Stoll, H. Managing the Design-Manufacturing Process, 1990 (McGraw-Hill, New York).

2 Syan, C. S. and Menon, U. Concurrent EngineeringConcepts, Implementation and Practice, 1994 (Chapman and Hall, London).
3 Wohlers, T. T. Rapid Prototyping and Tooling State of the Industry Annual Worldwide Progress Report, Wohlers Associates Inc., Colorado, 2000.

4 Anon, Selective laser sintered parts used directly in spacecraft production. Rapid Prototyping Report, Vol. 9, No. 11, November 1999.

5 Watson, K., Peterson, D. and Crockett, R. Application of solid freeform fabrication technology to NASA exploration missions. In Proceedings from the SFF Symposium, Austin, Texas, 1999, pp. 857-864.

6 Murphy, M. The future of additive manufacturing. Time Compression Technologies Mag., April 2000, 8(2).

7 Calder, N. Rapid manufacturing of functional materials. In Proceedings of the TCT2001 Conference, Manchester, 26-27 September 2001.

$8 \mathrm{http}: / /$ www.dtm-corp.com/applications/nasa.html (visited 24 November 2000).

$9 \mathrm{http}: / /$ www.3dsystems.com/index_nav.asp?nav=newsevents \&subnav $=$ news\&content $=$ newsevents $/$ newsreleases $/$ pr001122.asp (visited 24 November 2000).

10 Ayres, K. Translating STL files into X-files. In Proceedings of the TCT2001 Conference, Manchester, 26-27 September 2001.

11 Anon, Material data sheet fine polyamide PA 2200 for EOSINT P, EOS GmbH, Planegg, Germany. 